\title{
Prognostic Value of Preoperative Inflammation Markers in Non-Muscle Invasive Bladder Cancer
}

\author{
Hüseyin Alperen Yıldız ${ }^{1}$, Dogan Deger ${ }^{2}$, and Guven Aslan ${ }^{3}$ \\ ${ }^{1}$ Malazgirt State Hospital \\ ${ }^{2}$ Edirne State Hospital \\ ${ }^{3}$ Dokuz Eylül University
}

November 29, 2020

\begin{abstract}
Purpose: To investigate the prediction values of the preoperative NLR, LMR, PLR, MPV, RDW for recurrence and progression of patients with non-muscle invasive bladder cancer (NMIBC). Methods: In this prospective study, 94 consecutive patients, newly diagnosed with NMIBC between July 2017 - August 2018 were included. The blood samples were collected from patients before transurethral resection of bladder tumor (TURB) and NLR, LMR, PLR, RDW, MPV values were calculated. The effect of these preoperative inflammatory parameters and other clinicopathological parameters on recurrence and progression rates were evaluated. Kaplan-Meier and multivariate Cox regression analyses were performed to identify significant prognostic variables. Results: The mean follow-up was $11 \pm 6.4$ months. Recurrence was observed in $35.1 \%$ and progression was detected in $7.4 \%$ of the patients. Neutrophil-lymphocyte ratio was statistically significantly associated with both recurrence $(\mathrm{p}=0.01)$ and progression $(\mathrm{p}=0.035)$ whereas lymphocyte-monocyte ratio was only associated with recurrence $(\mathrm{p}=0.038)$. In the survival analyses, the relationship between recurrence and LMR was confirmed in both univariate $(\mathrm{p}=0.021)$ and multivariate $(\mathrm{p}=$ $0.022)$ analyses. The relationship between NLR and recurrence was confirmed in univariate analysis $(p=0.019)$, however in multivariate analysis was found to be statistically insignificant $(\mathrm{p}=0.051)$. Conclusions: Lymphocyte-monocyte ratio might be an easy obtainable, non-invasive and cost-effective method for predicting recurrence of disease in patients with non-muscle invasive bladder cancer.
\end{abstract}

Prognostic Value of Preoperative Inflammation Markers in Non-Muscle Invasive Bladder Cancer

Hüseyin Alperen Yıldız ${ }^{\text {a, }}$, Müslim Doğan Değer ${ }^{b}$, Güven Aslan ${ }^{c}$

a Department of Urology, Malazgirt State Hospital, Muş, Turkey

b Department of Urology, Edirne State Hospital, Edirne, Turkey

${ }^{c}$ Department of Urology, Dokuz Eylül University, School of Medicine, İzmir, Turkey

Short Title: Inflammation markers as a predictive tool in NMIBC

*Corresponding Author: Hüseyin Alperen Yıldız

Malazgirt State Hospital, Department of Urology

Address: Saltukgazi Mahallesi, Hastane Cd., Malazgirt, Muş, Turkey, 49400

Tel: +902324443511

E-mail: h.alperenyildiz@gmail.com

Acknowledgments: 
None

Disclosure Statement:

The authors have no conflicts of interest to declare.

Funding Sources:

The authors received no specific funding for this work.

\section{Hosted file}

text.pdf available at https://authorea.com/users/379749/articles/495943-prognostic-value-ofpreoperative-inflammation-markers-in-non-muscle-invas $\%$ C4\%B1ve-bladder-cancer

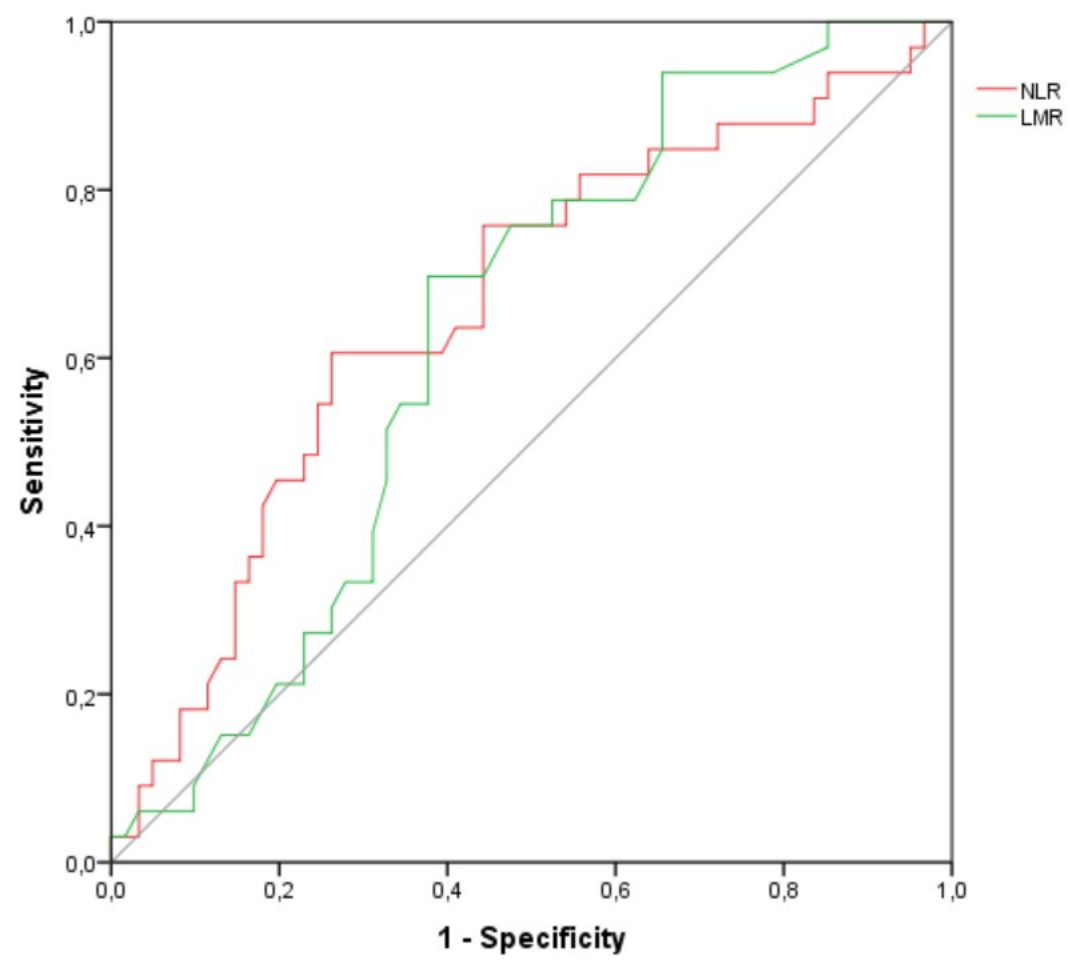



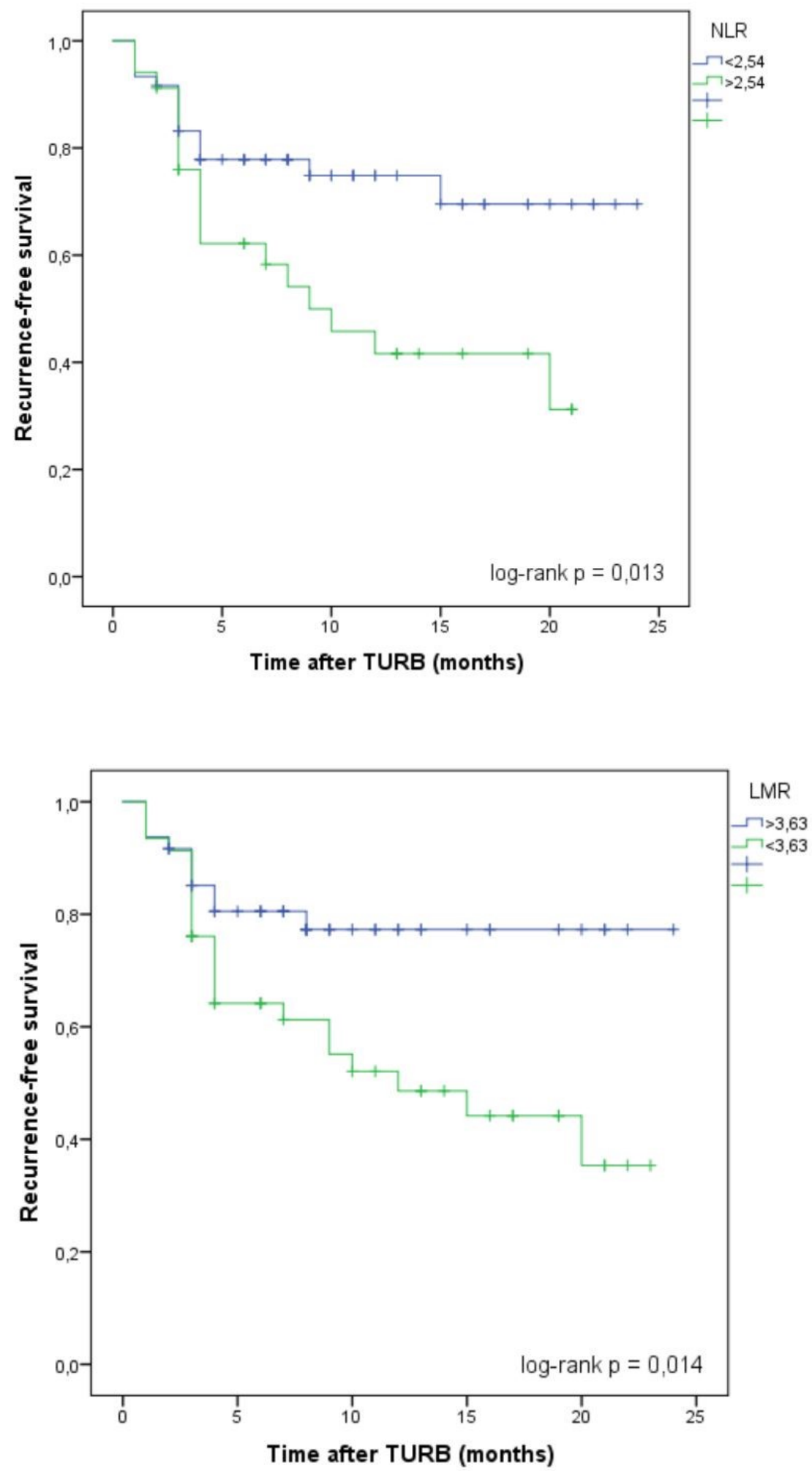